\title{
Синтез и исследование сорбента для ВЭЖХ на основе сополимера стирола и дивинилбензола, модифицированного наночастицами золота
}

\author{
Просунцова Д.С., Ананьева И.А., Плодухин А.Ю., \\ Белоглазкина Е.К., Шпигун О.А.
}

Московский государственный университет имени М.В. Ломоносова, Москва

Поступила в редакцию 26.01.2019 г.

DOI: https://doi.org/10.17308/sorpchrom.2019.19/731

Получен новый сорбент для ВЭЖХ на основе сополимера стирол-дивинилбензола, модифицированного наночастицами золота, стабилизированными липоевой кислотой с привитым лизином, и изучены его физико-химические и хроматографические свойства. Исследовано удерживание профенов и $\beta$-блокаторов на полученном сорбенте в зависимости от состава подвижной фазы. Установлено, что для профенов преобладает обращенно-фазовый механизм удерживания, в то время как для $\beta$ блокаторов комплексный.

Ключевые слова: ВЭЖХ, сополимер стирол-дивинилбензола, наночастицы золота, профены, $\beta$-блокаторы.

\section{Synthesis and study of a sorbent for HPLC based on a copolymer of styrene and divinylbenzene modified with gold nanoparticles}

\author{
Prosuntsova D.S., Ananieva I.A., Ploduhin A.U., \\ Beloglazkina E.K., Shpigun O.A. \\ Lomonosov Moscow State University, Moscow
}

\begin{abstract}
A new sorbent (CSD-Au-lipoic acid-lysine) for HPLC based on a styrene-divinylbenzene copolymer (CSD) was obtained by adsorption of gold nanoparticles (GNPs) on its surface, followed by modification of lipoic acid grafted with lysine. Self-assembled monolayers are readily formed by the reaction between sulfur, which lipoic acid contains, and gold surfaces. Low-temperature nitrogen adsorption, diffuse reflection spectroscopy, scanning electron microscopy were used to examine the physical and chemical properties of CSDAu-lipoic acid-lysine, as well as sorbents with lipoic acid-modified GNPs and L-cysteine- modified GNPs (CSD-Au-L-cysteine).

The hydrophobicity of CSD-Au-lipoic acid-lysine, CSD-Au-L-cysteine and unmodified CSD was estimated by the retention of aromatic compounds on the laboratory-made columns with these sorbents. The retention of these non-polar compounds was quite large, but differed slightly for three columns. It can be assumed that the hydrophobic properties of sorbents are determined predominantly by the polymer matrix.

The chromatographic behavior of profens and $\beta$-blockers on the obtained sorbents was studied depending on the composition of the mobile phase - the nature of the buffer solution, its concentration and $\mathrm{pH}$, the proportion of organic solvent and its nature. It was established that significant retention factors for both groups of substances are observed using the mixture of acetonitrile and buffer solution as the eluent. Herewith profens are kept longer with a lower content of organic solvent, and $\beta$-blockers, on the contrary. Hydrophobic interactions play a significant role in the retention of the studied compounds. The order of elution of
\end{abstract}


profens correlates with their hydrophobicity indices $\log \mathrm{P}, \log \mathrm{D}$. This dependence is traced to a lesser extent for $\beta$-blockers, due to the additional interactions. It was found that profens, which are organic acids with a $\mathrm{pK}$ value of $3.74-5.3$, are better retained and separated at a $\mathrm{pH}$ close to four, since as the $\mathrm{pH}$ rises, they dissociate into the carboxyl group and $\log \mathrm{D}$ decreases. The best chromatographic parameters for $\beta$-blockers, which are bases, are obtained at a $\mathrm{pH}$ close to seven, since their $\mathrm{pKa}$ take values from 8.8 to 9.7.

Thus, the reversed-phase retention mechanism predominantly is realized for profens on the studied sorbents, while for $\beta$-blockers, it is impossible to distinguish the main influence of one interaction, that is, a complex retention mechanism is implemented.

Keywords: HPLC, styrene-divinylbenzene copolymer, gold nanoparticles, profens, $\beta$-blockers.

\section{Введение}

Одной из наиболее актуальных задач современной высокоэффективной жидкостной хроматографии (ВЭЖХ) является разработка новых универсальных сорбентов, селективных к различным группам органических соединений. Большое внимание уделяется использованию различных наноматериалов, среди них выделяются наночастицы золота (НЧЗ), которые уже успешно применяются в методах разделения (капиллярном электрофорезе (КЭ) и капиллярной электрохроматографии (КЭХ)) [1-3]. Использование НЧЗ перспективно для получения новых сорбентов для ВЭЖХ, в первую очередь благодаря большой площади функциональной поверхности и многовариантности их модифицирования [4]. Чаще всего для стабилизации НЧЗ используют разнообразные серосодержащие соединения, поскольку они образуют на поверхности золота самоорганизованные монослои (COM) тиолятов за счет образования прочной ковалентной связи Au-S. Достоинством данной модификации является то, что она позволяет быстро и без специального оборудования получать однородные пленки на поверхности с контролируемой толщиной и заданными свойствами. Варьирование природы серосодержащих соединений позволяет синтезировать сорбенты с уникальными свойствами для конкретных аналитических задач. В ряде работ был использован силикагель для иммобилизации на его поверхность НЧЗ с последующей модификацией различными серосодержащими соединениями, что открыло новые подходы в решении тех или иных задач [5-10]. Силикагель - наиболее широко используемый сорбент в ВЭЖХ, однако, он не обладает высокой химической и гидролитической стабильностью, и на его поверхность присутствуют остаточные силанольные группы, оказывающие негативный эффект после модификации. В последнее время разрабатываются сорбенты на основе различных полимеров. Они обладают высокой химической, термической и механической стабильностью. В литературе довольно много исследований полимеров в качестве матриц для закрепления наночастиц [11]. В хроматографии наибольшее внимание среди сорбентов этой группы привлекают сополимеры стирола и дивинилбензола (ССД).

Целью настоящей работы являлось синтез нового сорбента на основе ССД, модифицированного НЧЗ, стабилизированными липоевой кислотой с привитым лизином, и изучение хроматографического поведения различных групп органических веществ на синтезированном сорбенте методом ВЭЖХ.

\section{Эксперимент}

Реагенты и аппаратура. Использовали стальные колонки (Phenomenex) размером 100×4.6 мм, которые набивали при помощи насоса «Knauer K-1900» под давлением 200-300 бар суспензионным методом. Исследование хроматографических свойств сорбента проводили на жидкостном хроматографе LC-20 Prominence («Shimadzu», Япония) с диодно-матричным детектором SPD-M20A («Shimadzu», Япония). 
Скорость подачи элюента составляла 0.3-0.5 см³/мин, объем петли дозатора 20 мкл. Для изучения физико-химических свойств нового сорбента использовали: атомноэмиссионный спектрометр с микроволновой плазмой Agilent 4200 («Agilent», США); сканирующий электронный микроскоп JEOL JCM-6000 (ускоряющее напряжение 20 кB, «JEOL», Япония); сканирующий денситометр CS-9001 3С («Shimadzu», Япония); ИК-спектрометр Nicolet iS10 FT-IR («Thermo Fisher Scientific», CША). Измерение площади поверхности и пористости методом низкотемпературнои адсорбции азота производили на приборе ASAP 2010 V2.00 A («Micromeritics», США).

Для синтеза сорбента в работе применяли следующие реагенты: $\mathrm{HAuCl}_{4} \cdot 3 \mathrm{H}_{2} \mathrm{O}$ (х.ч., «Merck», Германия), $\mathrm{Na}_{3} \mathrm{C}_{6} \mathrm{H}_{5} \mathrm{O}_{7} \cdot 2 \mathrm{H}_{2} \mathrm{O}$, (ос.ч., «Merck», Германия), L-цистеин (ос.ч.), липоевая кислота (х.ч.), БОК-лизин (х.ч.), $N, N$-дициклогексилкарбодиимида (х.ч.), $N, N$-диметиламинопиридина (х.ч.), трифторуксусная кислота (х.ч.), дихлорметан (х.ч.) («Рanreac», Испания). Для приготовления подвижных фаз (ПФ) использовали ацетонитрил, метанол, («для хроматографии», «Рanreac», Испания), триэтиламин (99\%, «Acros Organics», США), уксусную кислоту («Panreac», Испания). Для приготовления буферных растворов брали точные навески твердых и жидких препаратов ацетата аммония (х.ч.) («Реахим», Россия), дигидрофосфата калия («Panreac», Испания), тригидрата гидрофосфата калия («Рanreac», Испания), гидроксид натрия (х.ч.) («Реахим», Россия). В качестве исследуемых соединений использовали бензол, фенантрен, антрацен и различные $\beta$-блокаторы и профены, для анализа готовили

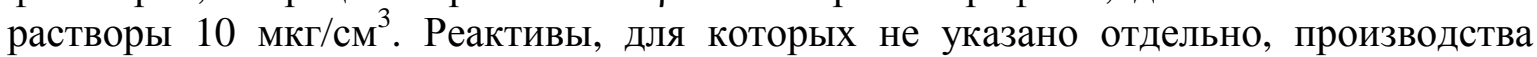
фирмы «SigmaAldrich» (CША).

Матрицей для сорбентов служил ССД, синтезированный д.х.н. Пироговым А.В. (кафедра аналитической химии, химический факультет МГУ), со следующими характеристиками: степень сшивки $50 \%$, размер частиц $3.3 \pm 0.2$ мкм, удельная площадь поверхности $200 \mathrm{~m}^{2} /$, общий объем пор $0.64 \mathrm{~cm}^{3} / \Gamma$, средняя длина пор 5 нм, средний диаметр пор 6 нм. Синтез наночастиц золота размером $10 \pm 2$ нм проводили по методу Туркевича [12], оптимизированному в работе [13].

Модифицирование поверхности ССД НЧЗ, стабилизированными цитратионами (ССД-Аи-цитрат). В круглодонной колбе при непрерывном перемешивании смешивали в деионизованной воде $60 \mathrm{~cm}^{3}$ раствора НЧЗ (10 нм) и 3 г частиц полистирола (3.3 мкм). Спустя 12 часов частицы ССД приобрели характерную лиловую окраску. Модифицированный ССД отфильтровывали на стеклянном пористом фильтре, промывали этанолом и высушивали на воздухе. Количество адсорбировавшегося золота определяли методом атомно-эмиссионной спектроскопии. Содержание золота в исходном образце составляет $0.09 \%$ или 0.914 мг на 1 г сорбента. Каждую последующую стадию синтеза подтверждали методом ИК-спектроскопии.

Получение ССД, модифицированного НЧЗ, стабилизированными липоевой кислотой (ССД-Аu-липоевая кислота). В круглодонной колбе при непрерывном перемешивании смешивали 3 г порошка ССД-Аи-цитрат и 200 мг липоевой кислоты в $70 \mathrm{~cm}^{3}$ деионизованной воды. Спустя 12 часов, порошок отфильтровывали на стеклянном пористом фильтре, промывали деионизованной водой, этанолом и высушивали на воздухе. На ИК-спектре были обнаружены линии 3626-3334 см ${ }^{-1}$, соответствующие водородным связям СООН-ООС и линия $1709 \mathrm{~cm}^{-1}$, соответствующая СО карбоксильной группы.

Получение ССД, модифицированного НЧЗ, стабилизированными липоевой кислотой с привитым БОК-лизином (ССД-Аи-липоевая кислота-БОК-лизин). В круглодонной колбе при непрерывном перемешивании смешивали 1 г сорбента ССД-Аи-липоевая кислота, 0.1 г БОК-лизина, 35 мг $N, N$-дициклогексилкарбодиимида, 3 мг $N, N$-диметиламинопиридина в $50 \mathrm{~cm}^{3}$ воды. Спустя 12 часов, по- 
рошок отфильтровывали на стеклянном пористом фильтре, промывали деионизованной водой, этанолом и высушивали на воздухе. На ИК-спектре были обнаружены линии: 3612-3259 $\mathrm{cm}^{-1}$ - водородные связи карбоксильной группы БОК-лизина; $3328 \mathrm{~cm}^{-1}$ - группа NH БОК-лизина, присоединенного к липоевой кислоте; 1725, $1702,1685 \mathrm{~cm}^{-1}$ - один карбонил липоевой кислоты и 2 карбонила БОК-лизина.

Получение ССД, модифицированного НЧЗ, стабилизированными липоевой кислотой с привитым лизином (ССД-Аи-липоевая кислота-лизин). К 4 см $50 \%$ раствора трифторуксусной кислоты в дихлорметане добавляли 1 г порошка ССД-Аuлипоевая кислота-БОК-лизин. Перемешивание проводили в течение 40 минут. Затем, порошок отфильтровывали на стеклянном пористом фильтре, промывали деионизованной водой, триэтиламином, этанолом и высушивали на воздухе. На ИК-спектре были обнаружены линии: 3589-3271 $\mathrm{cm}^{-1}$ - водородные связи карбоксильной группы лизина; 1720 и $1703 \mathrm{~cm}^{-1}-2$ карбонила липоевой кислоты с привитым лизином.

Синтез сорбента ССД, модифицированного НЧЗ, стабилизированными L-цистеином (CCД-Au-L-цистеин) проводили по методике, описанной в работе [14].

\section{Обсуждение результатов}

Для сравнения и лучшего понимания полученных результатов в работе исследовали 4 сорбента: CCД-Au-L-цистеин (сорбент 1), ССД-Au-липоевая кислота-лизин (сорбент 2), ССД-Аи-липоевая кислота (сорбент 3), немодифицированный ССД (сорбент 4). Поверхность сорбентов изучали методом сканирующей электронной микроскопии (СЭМ). На рис. 1 приведены микрофотографии ССД-Аи-липоевая кислотализин, как видно частицы имеют сферическую форму и равномерное распределение по размеру, который составляет 2-4 мкм, для остальных сорбентов получены те же результаты.

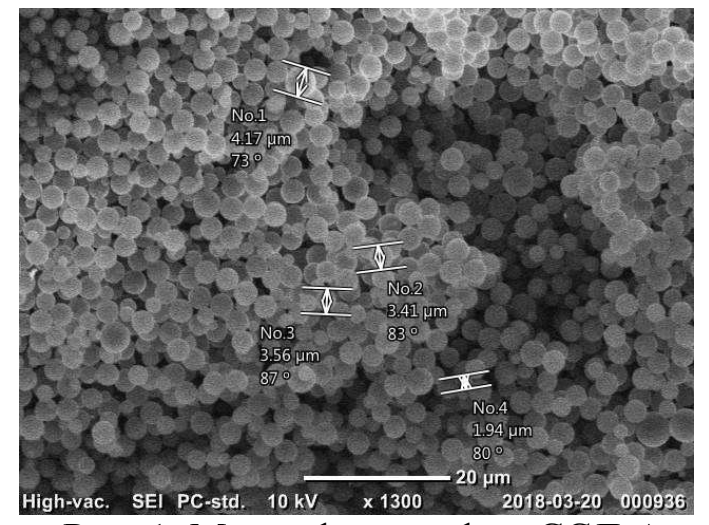

Рис. 1. Микрофотографии ССД-Аuлипоевая кислота-лизин.

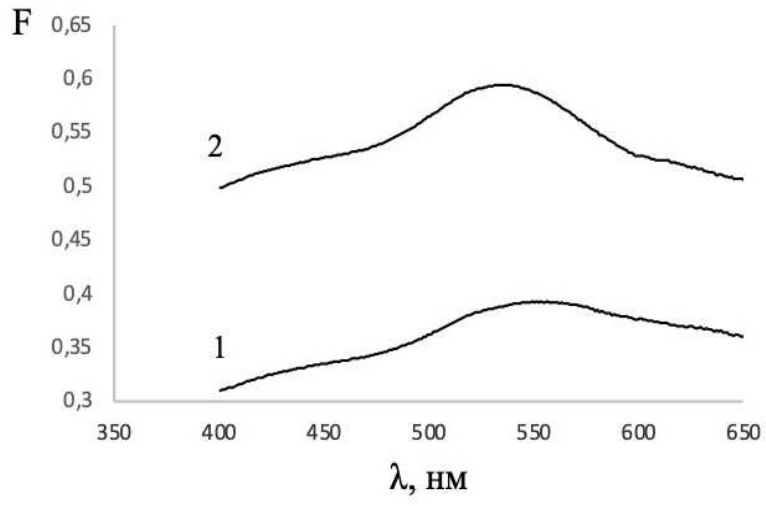

Рис. 2. Спектры диффузного отражения ССД-Аи-липоевая кислота-лизин (1), ССД-Au-L-цистеин (2).

Для исследования наличия золота на поверхности твердого носителя были сняты спектры диффузного отражения сорбента ССД-Аи-липоевая кислота-лизин и CCД-Au-L-цистеин (рис. 2). Спектры снимали в видимой области относительно немодифицированного ССД. Для обоих сорбентов наблюдается максимум поглощения в области 520-550 нм, что свидетельствует о наличии наночастиц золота на их поверхности [15]. Для сорбента с лизином максимум менее выражен и находится ниже, из чего можно сделать вывод, что в данном случае иммобилизация НЧЗ прошла хуже. 
Методом низкотемпературной адсорбции азота проводили оценку параметров поверхности сорбентов. По классификации Брунауэра-Деминга-Деминга-Теллера, изотермы сорбции для всех сорбентов относятся к IV типу, с петлей гистерезиса, вызванной протеканием процесса капиллярной конденсации в мезопорах, что говорит о полимолекулярной адсорбции на пористом адсорбенте. Выгнутый характер начального участка указывает на то, что взаимодействие адсорбент - адсорбат сильнее взаимодействия адсорбат - адсорбат. Из построенных изотерм сорбции были рассчитаны значения площади поверхности сорбентов, объем пор, средний диаметр пор согласно теории молекулярной адсорбции Брунауэра-Эмметта-Теллера (БЭТ). Данные представлены в табл. 1.

Таблица 1. Физические характеристики сорбентов по результатам исследования пористости.

\begin{tabular}{|c|c|c|c|}
\hline Сорбент & $\begin{array}{c}\text { Площадь } \\
\text { поверхности, м²/г }\end{array}$ & Объем пор, см ${ }^{3} / \Gamma$ & Средний диаметр пор, $\AA$ \\
\hline ССД & 301 & 0.49 & $65 \pm 13$ \\
\hline ССД-Аu-L-цистеин & 310 & 0.52 & $66 \pm 13$ \\
\hline $\begin{array}{c}\text { ССД-Аи-липоевая } \\
\text { кислота }\end{array}$ & 273 & 0.49 & $71 \pm 14$ \\
\hline $\begin{array}{c}\text { ССД-Аи-липоевая } \\
\text { кислота-Lуs }\end{array}$ & 557 & 0.65 & $47 \pm 9$ \\
\hline
\end{tabular}

Для сорбента ССД-Аи-липоевая кислота-лизин удельная площадь поверхности оказалась наибольшей и значительно превышающей площадь поверхности немодифицированного сополимера, что может быть следствием образования разветвлённой поверхности после модификации. Средний диаметр пор наименьший, а объем пор наибольший также для данного сорбента.

Для оценки гидрофобных свойств сорбентов были выбраны нейтральные соединения: бензол, фенантрен, антрацен. Гидрофобность веществ оценивали по параметрам Ханша $(\log \mathrm{P}, \log \mathrm{D})[16]$.

Как видно из табл. 2, ароматические углеводороды хорошо удерживаются на всех четырех колонках и элюируются в одинаковой последовательности (бензол

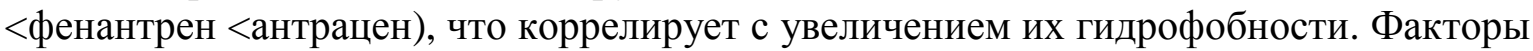
удерживания выше на колонках, заполненных сорбентами 2 и 3, где в модифицирующем слое присутствует липоевая кислота, содержащая углеродную цепочку, однако изменение в удерживании не велико. Вероятно, гидрофобность сорбентов при модифицировании изменяется незначительно, что говорит о преимущественном вкладе в нее полимерной матрицы. С увеличением содержания ацетонитрила в подвижной фазе удерживание веществ уменьшалось, что показывает существенный вклад гидрофобных взаимодействий в механизм удерживания аналитов.

При исследовании хроматографических свойств новых сорбентов были выбраны органические соединения различной природы: профены, представляющие собой органические кислоты, и $\beta$-блокаторы, которые проявляют основные свойства. Для выявления закономерностей их удерживания оценивали влияние природы буферного раствора в ПФ, его концентрации и $\mathrm{pH}$, доли органического растворителя и его природы на времена удерживания исследуемых соединений и эффективность колонки. Содержание органического растворителя варьировали в интервале от 70 до 90\%, при меньшем содержании - резко возрастало давление в колонке из-за набухания сорбента. 
Таблица 2. Факторы удерживания (k'), число теоретических тарелок (N), параметры гидрофобности $(\log \mathrm{P})$ исследуемых соединений. ПФ: ацетонитрил/буферный раствор ацетата аммония (20 мМ, pH=4.7) 90/10 (об. \%). Сорбент 1 - CCД-Au-L-цистеин; сорбент 2 - ССД-Аи-липоевая кислота-лизин; сорбент 3 - ССД-Аu-липоевая кислота; сорбент 4 - ССД.

\begin{tabular}{|c|c|c|c|c|c|c|c|c|c|}
\hline \multirow{2}{*}{$\begin{array}{c}\text { Исследуемые } \\
\text { вещества }\end{array}$} & & \multicolumn{2}{|c|}{ Сорбент 1} & \multicolumn{2}{|c|}{ Сорбент 2} & \multicolumn{2}{|c|}{ Сорбент 3} & \multicolumn{2}{|c|}{ Сорбент 4} \\
\hline & $\log \mathrm{P}$ & $\mathrm{k}^{\prime}$ & $\begin{array}{c}\mathrm{N} \\
\mathrm{TT} / \mathrm{M}\end{array}$ & $\mathrm{k}^{\prime}$ & $\begin{array}{c}\mathrm{N} \\
\mathrm{TT} / \mathrm{M}\end{array}$ & $\mathrm{k}^{\prime}$ & $\begin{array}{c}\mathrm{N} \\
\mathrm{TT} / \mathrm{M}\end{array}$ & $\mathrm{k}^{\prime}$ & $\underset{\mathrm{TT} / \mathrm{M}}{\mathrm{N}}$ \\
\hline Бензол & 2.22 & 1.40 & 4300 & 1.64 & 7300 & 1.53 & 8300 & 1.44 & 9000 \\
\hline Фенантрен & 4.68 & 10.52 & 2300 & 10.85 & 3600 & 10.88 & 3600 & 10.07 & 3900 \\
\hline Антрацен & 4.68 & 11.74 & 1500 & 12.26 & 2210 & 12.18 & 2600 & 11.25 & 3000 \\
\hline
\end{tabular}

Анализ экспериментальных данных показал, что для всех буферных растворов профены лучше удерживаются при $\mathrm{pH}$, близких к 4. При повышении $\mathrm{pH} \log \mathrm{D}$ этих веществ уменьшается в результате их диссоциации по карбоксильной группе, так как значения их рКа лежат в диапазоне 3.74-5.3 (табл. 3). При использовании ПФ, содержащих фосфатный буферный (ФБ) раствор, аналиты удерживаются значительно хуже, по сравнению с ацетатным (АБ) и ацетатом триэтиламина (ТЕАА) буферными растворами. На удерживание положительно влияет замена в подвижной фазе ацетонитрила (ACN) на смесь ацетонитрил-метанол $(\mathrm{MeOH})$.

Таблица 3. Факторы удерживания (k'), параметры гидрофобности $(\log \mathrm{P}, \log \mathrm{D})$ профенов (ПФ состава 40/40/20 (об. \%)). Сорбент 1 - ССД-Au-L-цистеин; сорбент 2 - ССД-Аи-липоевая кислота-лизин; сорбент 4 - ССД.

\begin{tabular}{|c|c|c|c|c|c|c|c|c|c|}
\hline \multirow{2}{*}{$\begin{array}{c}\text { Исследуемые } \\
\text { вещества }\end{array}$} & \multirow{2}{*}{$\log \mathrm{P}$} & \multicolumn{2}{|c|}{$\log$} & \multicolumn{3}{c|}{$\begin{array}{c}\text { ACN/MeOH/TEAA } \\
(0.05 \%, \mathrm{pH}=4)\end{array}$} & \multicolumn{3}{c|}{$\begin{array}{c}\text { ACN/MeOH/TEAA } \\
(0.05 \%, \mathrm{pH}=7)\end{array}$} \\
\cline { 3 - 11 } & & $\mathrm{pH}=$ & $\mathrm{pH}=$ & \multicolumn{3}{|c|}{$\mathrm{k}^{\prime}$} & \multicolumn{3}{c|}{$\mathrm{k}^{\prime}$} \\
\cline { 5 - 11 } & & 5.5 & 7.4 & 1 & 2 & 4 & 1 & 2 & 4 \\
\hline Индопрофен & 2.77 & 1.94 & 0.14 & 2.59 & 4.42 & 1.81 & 0.72 & 0.15 & 0.62 \\
\hline Кетопрофен & 2.81 & 1.83 & 0.06 & 3.16 & 2.39 & 2.00 & 0.63 & 0.25 & 0.72 \\
\hline Ибупрофен & 3.72 & 2.25 & 0.45 & 3.93 & 6.62 & 2.68 & 3.16 & 1.13 & 0.82 \\
\hline Флурбипрофен & 4.11 & 2.44 & 0.68 & 4.41 & 7.06 & 3.14 & 0.92 & 2.20 & 0.63 \\
\hline
\end{tabular}

Профены лучше удерживались на колонках с модифицированными ССД. Удалось разделить с хорошим разрешением три профена за 20 минут на колонке ССД-Аu-липоевая кислота-лизин на ПФ ацетонитрил/метанол/ТЭАА $(0.05 \%$, $\mathrm{pH}=4.0$ ) 40/40/20 (об. \%). Порядок выхода на трех колонках различается, что свидетельствует о реализации комплексного механизма удерживания, включающего не только гидрофобные, но и гидрофильные взаимодействия. В некоторых случаях это приводило к большой разнице в селективности. Так при разделении профенов коэффициенты селективности на немодфицированном ССД для индопрофена и кетопрофена $\alpha=1.1$, для кеторофена и ибупрофена $\alpha=1.34$, а на ССД-Аи-липоевая кислота- 
лизин для кетопрофена и индопрофена $\alpha=1.9$, для индопрофена и ибупрофена $\alpha=1.5$ (рис. 3).

Влияние содержания ацетонитрила в составе подвижной фазы на времена удерживания соединений проводили на ПФ состава: АСN/АБ (20 мМ, pH=4.3) 80/20 (об. \%) на сорбенте 2. Представленные на рис. 4 линейные зависимости с отрицательным наклоном для флурбипрофена и ибупрофена свидетельствует о реализации преимущественно обращено-фазового (ОФ) механизма удерживания за счет сольвофобных взаимодействий в ПФ, однако наблюдаемое отклонение от линейности для индопрофена и кетопрофена подтверждает наличие дополнительных взаимодействий.

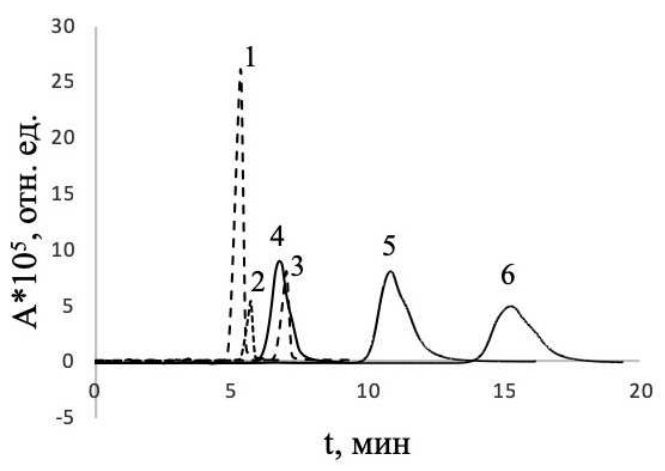

Рис. 3. Разделение профенов на колонках с ССД (1- индопрофен,

2- кеторофен, 3- ибупрофен) и с ССД-Аuлипоевая кислота-лизин (4- кетопрофен, 5 - индопрофен, 6- ибупрофен); подвижная фаза АCN/MeOH/TЭАА $(0.05 \%$, pH=4.0) 40/40/20 (об. \%). Скорость потока $0.5 \mathrm{~cm}^{3} /$ мин, $\lambda=230 \mathrm{Hм}$

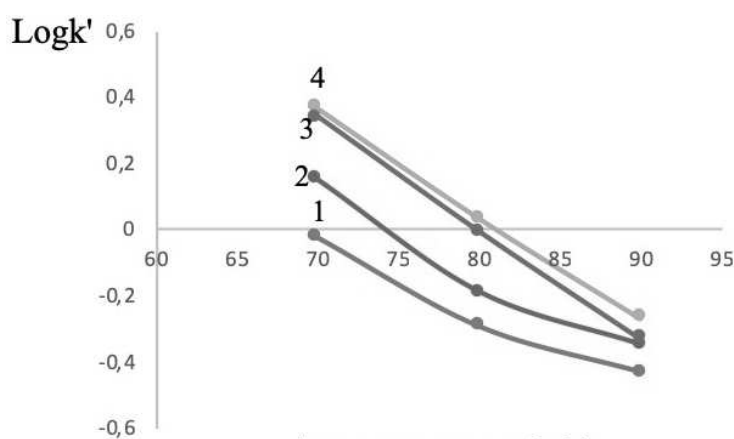

Ацетонитрил, об. \%

Рис. 4. Зависимость логарифма фактора удерживания профенов от доли ацетонитрила в ПФ: АСN/АБ (20 мМ, pH=4.3) 80/20 (об. \%) 1 - индопрофен, 2

- кетопрофен, 3 - флурбипрофен, 4 ибупрофен. Сорбент 2 - ССД-Аилипоевая кислота-Lys

$\beta$-блокаторы имеют высокие значения параметров гидрофобности $\log \mathrm{P}$, но в исследованной области $\mathrm{pH}$ их $\log \mathrm{D}$ принимают отрицательные значения, несмотря на это они хорошо удерживаются на использованных сорбентах. Удерживание $\beta$-блокаторов и селективность разделения увеличивались при $\mathrm{pH}$, близких к семи, так как их рКа принимают значения от 8.8 до 9.7, и $\log \mathrm{D}$ возрастает при больших $\mathrm{pH}$. Время удерживания исследуемых $\beta$-блокаторов росло при добавлении в ПФ ФБ и TEAА. В отличие от профенов, удерживание блокаторов возрастало с увеличением концентрации ацетонитрила в ПФ. Такой характер зависимости связан с изменением механизма удерживания сорбатов при высоком содержании полярного органического растворителя в подвижной фазе. При работе с подвижными фазами, содержащими от 90 до 100\% ацетонитрила или метанола, реализуется, так называемый, полярноорганический вариант жидкостной хроматографии. Распознавание в полярноорганическом варианте базируется на следующих взаимодействиях: образовании водородных связей, $\pi-\pi$ взаимодействиях, стерических затруднениях или электростатических взаимодействиях.

Как видно из табл. 4, удерживание и селективность разделения исследуемых веществ больше на модифицированных сорбентах. Шесть $\beta$-блокаторов удалось поделить за 15 минут на колонке, заполненной сорбентом ССД-Аи-липоевая кислотализин (рис. 5). 
Таблица 4. Факторы удерживания (k'), параметры гидрофобности $(\log \mathrm{P}, \log \mathrm{D})$ $\beta$-блокаторов. ПФ 1 - АCN/MeOH/ФБ (10 мМ, $\mathrm{pH}=6.8$ ) 40/40/20 (об. \%); ПФ 2 - ACN/MeOH/ФБ (10 мМ, pH=4.3) 40/40/20 (об. \%); ПФ 3 - АCN/MeOH/ТЭАА $(0.05 \%, \mathrm{pH}=4)$ 40/40/20 (об. \%). Сорбент 1 - ССД-Au-L-цистеин; сорбент 2 - CCД-Auлипоевая кислота-лизин; сорбент 4 - ССД.

\begin{tabular}{|c|c|c|c|c|c|c|c|c|c|c|c|}
\hline \multirow[b]{2}{*}{$\begin{array}{c}\text { Исследуемые } \\
\text { вещества }\end{array}$} & \multicolumn{2}{|c|}{$\log \mathrm{D}$} & \multicolumn{3}{|c|}{ Сорбент 1, k’ } & \multicolumn{3}{|c|}{ Сорбент 2, k' } & \multicolumn{3}{|c|}{ Сорбент 4, k' } \\
\hline & $\begin{array}{l}\mathrm{pH} \\
5.5\end{array}$ & $\begin{array}{l}\mathrm{pH} \\
7.4\end{array}$ & $\bar{\theta}$ & 光 & $\hat{\theta}$ & $\vec{\theta}$ & $\tilde{\Theta}$ & $\hat{\theta}$ & $\vec{\theta}$ & $\stackrel{v}{\theta}$ & $\stackrel{n}{\theta}$ \\
\hline $\begin{array}{c}\text { Атенолол } \\
\log \mathrm{P}=0.1\end{array}$ & -2.8 & -1.9 & 0.83 & 0.19 & 1.41 & 0.77 & 0.67 & 2.06 & 0.49 & 0.56 & 1.09 \\
\hline $\begin{array}{c}\text { Окспренолол } \\
\log \mathrm{P}=2.29\end{array}$ & -0.8 & -0.2 & 4.05 & 1.11 & 2.2 & 3.89 & 1.79 & 3.66 & 2.25 & 0.75 & 1.74 \\
\hline $\begin{array}{l}\text { Пиндолол } \\
\log \mathrm{P}=1.97\end{array}$ & -1.2 & -0.3 & 1.98 & 0.48 & 2.03 & 2.4 & 1.26 & 1.06 & 1.22 & 0.18 & 1.54 \\
\hline $\begin{array}{c}\text { Лабеталол } \\
\log \mathrm{P}=2.31\end{array}$ & -0.3 & -0.9 & 2.37 & 1.08 & 2.78 & 2.7 & 2.28 & 3.75 & 1.63 & 0.89 & 1.9 \\
\hline $\begin{array}{c}\text { Метопролол } \\
\log \mathrm{P}=1.79\end{array}$ & -1.2 & -0.3 & 3.03 & 1.0 & 2.05 & 3.06 & 157 & 4.06 & 1.91 & 0.76 & 1.78 \\
\hline $\begin{array}{c}\text { Алпренолол } \\
\log \mathrm{P}=2.88\end{array}$ & -0.3 & 0.7 & 5.78 & 1.34 & 2.18 & 5.41 & 2.37 & 3.48 & 3.15 & 1.02 & 2.17 \\
\hline $\begin{array}{c}\text { Надолол } \\
\log \mathrm{P}=1.29\end{array}$ & -1.8 & -0.9 & 1.4 & 0.53 & 1.68 & 1.58 & 0.89 & 2.48 & 0.75 & 0.48 & 1.13 \\
\hline
\end{tabular}
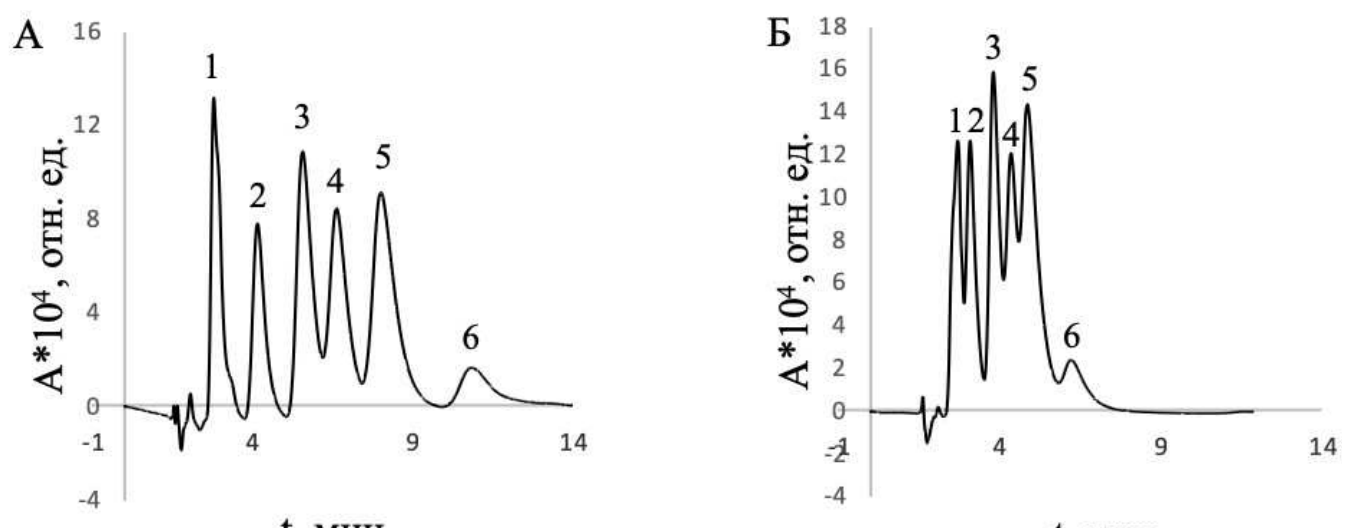

t, мин

$\mathrm{t}$, мин

Рис. 5. Хроматограммы смеси $\beta$-блокаторов: 1 - атенолол, 2 - надолол,

3 - пиндолол, 4 - метопролол, 5 - окспренолол, 6 - алпренолол. ПФ ацетонитрил/метанол/ФБ (10 мМ) 40/40/20 (об. \%); А - pH=6.8, Б - pH=4.3. Сорбент 2 - ССД-

$\mathrm{Au}$-липоевая кислота-лизин. Скорость потока $\mathrm{F}=0.5 \mathrm{~cm}^{3} / \mathrm{мин,} \lambda=230 \mathrm{нм.}$

Хорошо известно, что большинство $\beta$-блокаторов хиральны и их энантиомеры несут различный потенциальный и фармакологический эффекты. В ходе изучения хроматографического поведения $\beta$-блокаторов наблюдались случаи частичного разделения их энантиомеров на исследуемых сорбентах.

\section{Заключение}

Синтезирован новый сорбент для ВЭЖХ - сополимер стирол-дивинилбензол, модифицированный наночастицами золота, стабилизированными липоевой кислотой 
с привитым лизином. Показано, что сорбент обладает гидрофобными свойствами. Исследовано влияние состава подвижной фазы на факторы удерживания профенов и $\beta$-блокаторов. Установлено, что на порядок выхода $\beta$-блокаторов влияет гидрофобность молекул, наличие и расположение полярных групп, реализуется смешанный механизм удерживания; в удерживании профенов преобладает обращенно-фазовый механизм. Предложены условия разделения смеси $\beta$-блокаторов (атенолол, надолол, пиндолол, метопролол, окспренолол, алпренолол) за 15 минут и трех профенов (кетопрофен, индопрофен, ибупрофен (флурбипрофен)) за 20 минут.

Работа выполнена при финансовой поддержке РФФИ №18-03-00742.

\section{Список литературы}

1. Nilsson C., Nilsson S. // Electrophoresis. 2006. Vol. 27. pp. 76-83. DOI: 10.1002/elps.200500535

2. Palmer C.P., McCarney J.P. // Electrophoresis. 2004. Vol. 25. pp. 4086-4094.

3. Moliner-Martinez Y., Cardenas S., Simonet B. M., Valcarcel M. // Electrophoresis. 2009. Vol. $30 . \quad$ pp. 169-175. DOI: 10.1002/elps.200800314

4. Nesterenko E. P., Nesterenko P. N., Connolly D., He X., Floris P., Duffy E., Paull B. // Analyst. 2013. Vol. 138. P. 4229-4254. DOI: 10.1039/C3AN00508A

5. Ананьева И.А., Елфимова Я.А., Мажуга А.Г., Рудаковская П.Г. и др. // Сорбиионные и хроматографические прочессы. 2011. Т. 11. № 3. C. 281-291.

6. Qu Q., Peng S., Mangelings D., Hu X., Yan C. // Electrophoresis. 2010. Vol. 31. pp. 556562. DOI: $10.1002 /$ elps.200900375

7. Liu F.K., Wei G.T., Cheng F.C. // Chin. J. Chem. Soc. 2003. Vol. 50. pp. 931-937.

8. Шаповалова Е.Н., Ананьева И.А., Елфимова Я.А., Гринева Л.А. и др. // Вестн. Моск. ун-та. Сер. 2. Химия. 2012. Т. 53. № 2. С. 108-114.

9. Elfimova Ya.A., Pichugina D.A., Anan'eva I.A., Mazhuga A.G. et al. // Journal of Physical Chemistry A. 2012 Vol. 86. No 10. pp. 16231629. DOI: $10.1134 / \mathrm{S} 0036024412100081$

\section{References}

1. Nilsson C., Nilsson S., Electrophoresis, 2006, Vol. 27, pp. 76-83. DOI: 10.1002/elps.200500535

2. Palmer C.P., McCarney J.P., Electrophoresis, 2004, Vol. 25, pp. 4086-4094.

3. Moliner-Martinez Y., Cardenas S., Simonet B. M., Valcarcel M., Electrophoresis, 2009,
10. Елфимова Я.А., Ананьева И.А., Мажуга А.Г., Шпигун О.А. // Заводск. лаборатория. Диагностика материалов. 2012. Т. 78. № 6. C. 20-27.

11. Mahouche-Chergui S., Guerrouache M., Carbonnier B., Chehimi M.M. // Colloids and Surfaces A: Physicochem. Eng. Aspects. 2013. Vol. 439. pp. 43-68. DOI: 10.1016/j.colsurfa.2013.04.013

12. Turkevich J., Stevenson P.C., Hillier J. // Discuss. Faraday Soc. 1951. Vol. 11. pp. 55-75.

13. Рудаковская П.Г. Новые бифункциональные органические лиганды для модификации наночастиц золота и магнетита и гибридные материалы на их основе: синтез, свойства, возможности применения. Дисс. канд. хим. наук. М. 2015. 185 с.

14. Полякова Я.А. Новые гибридные функциональные материалы на основе наночастиц золота для ВЭЖХ. Дисс. канд. хим. наук. М. 2013. 190 с.

15. Amendola V., Meneghetti M., Stener M., Guo Y., Chen S., Crespo P., García M., Hernando A., Pengo P., Pasquato L. // Comprehensive Analytical Chemistry. 2014. Vol. 66. pp. 81-152.

16. Долгоносов А.М., Рудаков О.Б., Прудковский А.Г. Колоночная аналитическая хроматография: практика, теория, моделирование. СПб. Лань. 2015. 468 с.

Vol. $\quad 30, \quad$ pp. 169-175. DOI: 10.1002/elps.200800314

4. Nesterenko E.P., Nesterenko P.N., Connolly D. et al., Analyst, 2013, Vol. 138, pp. 42294254. DOI: $10.1039 / \mathrm{C} 3 \mathrm{AN} 00508 \mathrm{~A}$

5. Ananieva I.A., Elfimova Ya.A., Mazhuga A.G., Rudakovskaya P.G. et al., Sorbtsionnye $i$ 
khromatograficheskie protsessy, 2011, Vol. 11, No 3, pp. 281-291.

6. Qu Q., Peng S., Mangelings D., Hu X., Yan C., Electrophoresis, 2010, Vol. 31, pp. 556-562. DOI: 10.1002/elps.200900375

7. Liu F.K., Wei G.T., Cheng F.C., Chin. J. Chem. Soc., 2003, Vol. 50, pp. 931-937.

8. Shapovalova E.N., Ananieva I.A., Elfimova Ya.A., Grinyova L.A. et al., Bulletin of the Moscow university. Chemistry series, 2012, Vol. 53, No 2, pp. 108-114.

9. Elfimova Ya.A., Pichugina D.A., Anan'eva I.A., Mazhuga A.G. et al., Journal of Physical Chemistry A, 2012, Vol. 86, No 10, pp. 16231629. DOI: $10.1134 / \mathrm{S} 0036024412100081$

10. Elfimova Ya.A., Ananieva I.A., Mazhuga A.G., Shpigun O.A., Zavodskaya laboratoriya. Diagnostika materialov, 2012, Vol. 78, No 6. pp. 20-27.

Просунцова Дарья Сергеевна - аспирант кафедры аналитической химии, Московский государственный университет имени М.В. Ломоносова, Химический факультет, Москва

Ананьева Ирина Алексеевна - старший научный сотрудник кафедры аналитической химии, к.х.н., Московский государственный университет имени М.В. Ломоносова, Химический факультет, Москва

Плодухин Андрей Юрьевич - студент третьего курса, Московский государственный университет имени М.В. Ломоносова, Химический факультет, Москва

Белоглазкина Елена Кимовна - профессор кафедры органической химии, д.х.н., Московский государственный университет имени М.В. Ломоносова, Химический факультет, Москва

Шпигун Олег Алексеевич - профессор кафедры аналитической химии, д.х.н., Московский государственный университет имени М.В. Ломоносова, Химический факультет, Москва
11. Mahouche-Chergui S., Guerrouache M., Carbonnier B., Chehimi M.M., Colloids and Surfaces A: Physicochem. Eng. Aspects, 2013, Vol. 439, pp. 43-68. DOI: 10.1016/j.colsurfa.2013.04.013.

12. Turkevich J., Stevenson P.C., Hillier J., Discuss. Faraday Soc., 1951, Vol. 11, pp. 5575.

13. Rudakovsky P.G. Diss. cand. chem. science. M., 2015, 185 p.

14. Polyakova Ya.A. Diss. cand. chem. science, M., 2013, $190 \mathrm{p}$.

15. Amendola V., Meneghetti M., Stener M., Guo Y. et al., Comprehensive Analytical Chemistry, 2014, Vol. 66, pp. 81-152.

16. Dolgonosov A.M., Rudakov O.B., Prudkovsky A.G. Kolonochnaya analiticheskaya hromatografiya: praktika, teoriya, modelirovanie.. SPb., Lan’ Publ., 2015. 468 p.

Prosuntsova Daria S. - the postgraduate student, department of analytical chemistry, Lomonosov Moscow State University, Chemistry Department, Moscow, E-mail: inhusoria6@yandex.ru

Ananieva Irina A. - Senior Researcher, Ph.D (chemistry), department of analytical chemistry, Lomonosov Moscow State University, Chemistry Department, Moscow, E-mail: irishan@mail.ru

Ploduhin Andrey U. - 3rd year student, Lomonosov Moscow State University, Chemistry Department, Moscow, E-mail: ploduhin.a@gmail.com

Beloglazkina Elena K. - prof., grand Ph.D (chemistry), department of organic chemistry, Lomonosov Moscow State University, Chemistry Department, Moscow, E-mail: beloglazki@mail.ru

Shpigun Oleg A. - prof., grand Ph.D (chemistry), department of analytical chemistry, Lomonosov Moscow State University, Chemistry Department, Moscow, E-mail: shpiguno@yandex.ru 